\title{
ОСОБЕННОСТИ ОРГАНИЗАЦИИ И МЕХАНИЗМЫ ДЕЯТЕЛЬНОСТИ МЕСТНЫХ ПЕРЕПИСНЫХ ОРГАНОВ В ПЕРИОД СЕЛЬСКОХОЗЯЙСТВЕННОЙ ПОЗЕМЕЛЬНОЙ И ВСЕРОССИЙСКОЙ ГОРОДСКОЙ ПЕРЕПИСИ 1917 ГОДА (ПО МАТЕРИАЛАМ ТОМСКОЙ ГУБЕРНИИ)
}

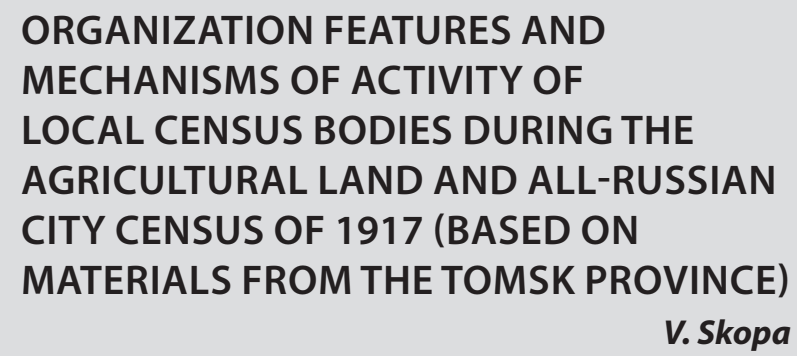

ORGANIZATION FEATURES AND

MECHANISMS OF ACTIVITY OF

LOCAL CENSUS BODIES DURING THE

AGRICULTURAL LAND AND ALL-RUSSIAN

CITY CENSUS OF 1917 (BASED ON

MATERIALS FROM THE TOMSK PROVINCE)

V. Skopa

Summary: The article discusses the features of the organization and mechanisms of the census bodies in the Tomsk province during the agricultural land and the All-Russian city census of 1917. The pattern of the division of the province and the distribution of functionality among the counter-registrars is determined. The work of the census office managers is systematically presented. The mechanism of interaction between regional authorities and census staff is shown. In conclusion, a conclusion is drawn about the comprehensive instructive and methodological support of statistical work and the systematic presentation of the generated material.

Keywords: census, statistical accounting, registrar, Tomsk province, statistics.

\author{
Скопа Виталий Александрович \\ Д.и.н., Алтайский государственный педагогический \\ университет, г. Барнаул \\ sverhtitan@rambler.ru
}

Аннотация: В статье рассматриваются особенности организации и механизмы деятельности переписных органов в Томской губернии в период сельскохозяйственной поземельной и всероссийской городской переписи 1917 года. Определена схема деления губернии и распределение функционала среди счетчиков-регистраторов. Системно представлена работа заведующих переписными участками. Показан механизм взаимодействия региональных властей и переписного персонала. В заключении делается вывод о комплексном инструктивно-методическом обеспечении статистических работ и системном представлении сформированного материала.

Ключевые слова: перепись, статистический учет, регистратор, Томская губерния, статистик.
$\mathrm{H}$ ачиная со второй половины XIX века теоретико-методологическая основа статистических обследований существенно изменилась и, этому способствовало развитие науки, в первую очередь статистической, накопленный опыт статистических работ, а также функционирование на местах региональных статистических центров в лице губернских и областных статистических комитетов, аккумулирующих практику статистических обследований.

В территориальных границах Томской губернии организация и проведение всероссийских статистических кампаний, региональных статистических работ всецело возлагалась на статистический комитет, который в свою очередь оперативно определял функционал региональной статистической сети, структурными дефинициями которой были привлекаемые органы административнотерриториального управления - уездные и волостные правления; административно-полицейский аппарат; добровольные статистические корреспонденты в лице местных обывателей; переписные комиссии, формируемые в период статистических кампаний; ссыльные и переселенцы, проявлявшие желание участвовать в статистических обследованиях, а так же статистические отделы городских и земских управ, где земские в регионе начали функционировать с 1917 г. [1, с. 152].

Начиная с XX столетия интенсивность статистических работ в регионе была существенно увеличена, что объясняется необходимостью репрезентативного статистического материала отраслевого характера в условиях диверсифицированного его использования, в первую очередь для решения административных задач и принятия управленческих решений, что привело к расширению региональной статистической сети. Непосредственное руководство всеми работами по сельско- 
хозяйственной поземельной переписи 1917 года в Томской губернии было возложено на статистический отдел Томского переселенческого района.

Bсе определенные работы по переписи, как в отношении вопросов программного, так и вопросов организационного характера, велись в соответствии IV сибирского областного съезда статистиков, а также с постановлениями местного совещания по переписи, в состав которого входили представители науки, местных общественных и партийных организаций, правительственных учреждений и отдельные лица, в качестве сведущих людей [2, с. 10].

Организационная часть работ по переписи возлагалась на оформленное бюро, в состав которого входили: заведующий статистическим отделом, его помощник и пять человек из числа сотрудников статистического отдела, принимавших участие во всех работах по переписи 1916 года. Все члены бюро пользовались правом решающего голоса.

Для системного формирования статистического материала была проработана схема деления губернии. Для производства переписи Томская губерния делилась на следующие переписные единицы: округа, инструкторские районы и регистраторские участки. В состав каждого округа входило от 40000 до 60000 хозяйств. Инструкторских районов в состав округа входило около 5-9, каждый из которых состоял из 2-3 волостей и 4000-6000 хозяйств. Регистраторские участки включали в среднем 620-640 хозяйств [3, л. 59]. Данное районирование позволяло системно формировать материал и оперативно обработанные данные, без промедления и задержки, представлять в высшую инстанцию, которой являлся переселенческий район губернии.

На основе анализа инструкционно-методических руководств, спущенных в регионы, важнейшим звеном в организации и проведении переписной кампании являлся проработанный механизм деятельности местных переписных органов. Так, определялось каким образом и как будут взаимодействовать местные органы власти с переписными структурами. В рекомендациях и методических наставлениях указывалось «содействие переписи в административном отношении», что определяло активную позицию региональных властей. Данная часть предусматривала, что содействие переписи в административном отношении возлагается на местные исполнительные комитеты городских, уездных, районных, волостных и сельских народных собраний, а также полосу отчуждения железных дорог - на местные комитеты железнодорожных организаций. Далее отмечалось, что «названные комитеты обязаны оказывать всемерное содействие тому, чтобы перепись прошла успешно и в кратчайший срок» [3, л. 62].
В соответствии с этими рекомендациями на исполнительные комитеты возлагались следующие обязанности: заботиться о срочном созыве сельских сходов, о срочном снаряжении лошадей и подвод для разъездов и посылки нарочных устройств переправ и о предоставлении других средств передвижения для переписного персонала (дрезины, лодки и т.п.)» [4, л. 186]. К тому же, предоставлялись безвозмездно для работы и жилья работающим по переписи квартиры. В случаях, когда переписной персонал обращался за разъяснениями или содействиями, то ему необходимо было помогать, представляя «официальные материалы и данные, касающихся крестьянского хозяйства и вопросов земельного и продовольственного» [4, л. 195]. Для более успешной коммуникативности, при проведении переписных мероприятий в губернии, подыскивали в помощь переписному персоналу «надежных и хорошо грамотных людей, знающих местную жизнь и преданных народным интересам», что позволяло избегать сложностей и непонимания со стороны местного населения [4, л. 201]. В работе счетчикам приходилось разъяснять населению значение переписи и следить за тем, чтобы все правдиво сообщали требуемые переписью сведения, поскольку самим задействованным членам в переписном мероприятии перепроверить было невозможно в силу недостатка времени.

На исполнительные комитеты возлагалось наблюдение за переписным штатом, чтобы «лица исполняли свой служебный долг не нарушали интересов народных и государственных» [5, л. 221]. Данный контроль в основном носил формальный характер, поскольку счетчики сами прекрасно понимали степень ответственности за выполнение поставленных задач.

В обозначенной схеме отдельное место определялось заведующим переписных единиц, куда относили окружных, районах инструкторов и участковых регистраторов. Их в основном представляли прикомандированные из разных учреждений, которые поступали в распоряжение переписной организации. Круг полномочий и обязанностей заведующих переписными участками определялся рядом положений. Так, окружные инструктора являлись представителями губернской переписной организации и наделялись наибольшей распорядительной властью в отношении переписного персонала и производства переписи. В распоряжение окружных инструкторов отпускались денежные средства, которые предназначались для производства переписи в данном округе [6, с. 235-249]. Отдельным документом регламентировались обязанности окружных инструкторов. Основной круг функционала сводился «к руководству за деятельностью переписного персонала по вопросам программного и организационного характера; наблюдение за деятельностью инструкторов в отношении целесообразности соответствия требованиям 
инструкции; наблюдение за ходом переписи; рассмотрение и разрешение всех конфликтов внутри переписного персонала, а также между сотрудниками переписи и населением; прием от районных инструкторов материалов переписи, денежного и технического отчета о ее производстве; организация подсчитанных работ в округе; ответственность за полноту и правильность регистрации подсчета в округе; срочная доставка переписного материала в Томск; оплата труда сотрудников переписи и прочих расходов переписи в округе; представление заведующему переписью технического и денежного отчета о производстве переписи в округе; приглашение по мере надобности и обучение инструкторов счетчиков и др. сотрудников переписи и т.п.» [5, л. 228]. Фактически фигура окружного инструктора и его деятельность являлась главенствующей и, во многом, определяющей при разрешении любых вопросов в границах округа.

Следующую ступень в организации переписной кампании представляли районные инструктора, на которых возлагались определенные обязанности. Так, «по прибытии на место, им необходимо было войти в отношения с местными исполнительными комитетами для ознакомления с положением и особенностями местности и населения, для более удобного разделения, содействии Комитетов, инструкторского района на участки регистраторские, для получения маршрутов и т.п.» [5, л. 229]. Отдельное внимание было уделено организационной части дела. Руководствуясь полученными в губернской переписной организации списком персонала, районный инструктор обязан был пригласить и обучить регистраторов, разъясняя им цели и задачи переписи, а также значение переписных формуляров и способы заполнения их. По необходимости окружной инструктор обязан был снабжать регистраторов бланками и инструкционными руководствами, предваряя «четким комментированием к материалу и делая поправки на возможные ошибки и допускаемые неточности» [5, л. 232].

По мере выполнения работ районный инструктор осуществлял систематический контроль работы регистраторов, посещая каждого за весь рабочий период. Так, в инструкционной записке прописывалось «для сего инструкторам рекомендуется следующее: прослушивать, правильно ли регистратор ведет опрос и делает записи и давать соответствующие указания, инструктор знакомится с регистрационным материалом, затем вызывает или навещает на дому уже опрошенных крестьян и подвергает их вторичному опросу, делая на соответствующих формулярах исправления или записи второй строкой (другими по цвету чернилами или графическим карандашом). Из других способов контроля инструкторов можно рекомендовать проверку скота в селении путем опроса или просмотра окладных книг; выяснения площади посевных занятых различными культурами, задаванием вопроса о количестве высеянных семян; срав- нение посевной площади с общей площадью пахотной земли и т.п.» [7, с. 97-115]. Данные наставления районным инструкторам, на практике во многом являлись незаменимым подспорьем, и позволяли избегать неточностей и ошибок.

Отдельное внимание при производстве переписи со стороны районного инструктора обращалось на заполнение личных карточек персоналом. Здесь учитывалась и быстрота, и успешность работы регистраторов, а также их отношение к делу. Районный инструктор еженедельно сообщал заведующему переписью посредством почты краткие сведения о ходе работ с представлением копии сообщения окружному инструктору. В важных, как отмечалось в дополнительном пояснении «необходимо уведомлять о положении дела заведующего округом по телеграфу, с сообщением копии заведующему переписью в губернии» [5, л. 389]. По окончанию работ, в инструкционном наставлении прописывалось, что в пятидневный срок необходимо представить окружному инструктору, вместе с заполненной анкетой, программы обследований, отчет о положении и работ в инструкторском районе. Данная деятельность сводилась к верификации полученных данных и формированию аналитической записки о проделанной работе.

Что касается организации работ регистраторов, то они производили перепись в назначенном ему инструктором участке и руководствовались общими инструкциями по производству сельскохозяйственной и земельной переписи, вели дневник, заполняли анкетный лист, готовили отчетность на общих основаниях. Фактически они выполняли текущую работу в производстве переписной кампании. Во многом, именно от регистраторов зависела адекватность и репрезентативность формируемого материала [8, с. 59]. В этой связи, организаторы переписи уделяли внимание отработке переписных приемов не только в теории, но и на практике, до начала самой переписи: заполняя тренировочные листы.

В целях определения степени достоверности полученных материалов переписи по окончании первичной регистрации, делалась установка производить повторную перепись. Данное мероприятие производилось обязательно инструктором и представляло собой вторичный опрос уже ранее опрошенных домов, причем результаты опроса заносились на отдельную подворную карточку. Карточки подворной переписи не были объединены с материалами первичной регистрации. Они отдельно от них предоставлялись окружному инструктору при отчете о производстве переписи. Вторичному опросу в каждом инструкторском районе подвергалось не менее 60 домохозяев в разных селениях, указанных окружным инструктором. В последствии он по получении карточек повторного опроса, путем подсчета итогов, заключающихся в них и в соответствующих карточ- 
ках первичной регистрации, составлял сравнительные таблицы по округу и предоставлял их в губернскую переписную организацию [3, л. 209]. Повторная выборка материала позволяла удостовериться в верности полученных сведений и их соответствии.

Отличительные особенности и специфические черты имела организация переписи в городах. Ключевые мероприятия переписной кампании возлагались на окружных инструкторов, которые руководствовались в своей деятельности инструкцией и также указаниями исполнительных комитетов городских народных собраний и заменяющих их органов. Предваряла перепись деятельность окружного инструктора, совместно с городским исполнительным комитетом по установлению пределов распространения городской переписи с полным перечнем прилегающих к городу населенных мест, которые подлежали исследованию по программе статистического обследования.

Следующим этапом работы являлось составление плана города или исправления существующего и его деление на участки и кварталы. Так, перепись в городах Сибири производилась с приближением к типу однодневных переписей и все сведения фиксировались на определенное число, само же выполнение переписи могло продолжаться в течение 4-6 дней.

В плане подготовки счетчиков для городской переписи механизм был схожим с сельскохозяйственной переписной кампанией. Отдельное внимание инструкторы обращали на специфику заполнения статистических форм и их представление. Так же определялась рабочая норма для регистраторов-переписчиков, которая заключалась в минимальном количестве карточек в рабочий день, и она равнялась 40 штукам [5, л. 351]. Все подготовительные к переписи работы и сама перепись, в пределах намеченной отделом переписи программы, производилась за счет средств, отпущенных в распоряжение переписной организации. Норма вознаграждения персонала устанавливалась на местах инструктором, по соглашению с городским исполнительным комитетом, в зависимости от местных условий.

В организационной части переписной кампании отдельное внимание было обращено на статистическую фиксацию в полосе отчуждения железных дорог. В инструкционном руководстве подробно прописывался механизм выполнения работ и формирования данных, где отмечалось, что «организация переписи в полосе отчуждения возлагалась на заведующих переписными округами; для каждого участка пути формировался отряд переписчиков во главе с руководителем; этот отряд подразделялся на несколько групп; каждая такая группа вела обследование в своем участке; передвижение в пределах участка, в случае невозможности пользования поездами, производилась на дрезинах» [5, л. 384].

Самостоятельным разделом инструкционного руководства являлись наставления работникам (счетчикам), задействованным в проведении переписи, а именно в части правильного выстраивания диалога. В указаниях прописывалось «сотрудники переписи всех категорий должны вести себя вполне безупречно в нравственном отношении, как того требует важность настоящих переписных работ» [5, л. 393].

При зачислении в ряды счетчиков каждый сотрудник давал переписной организации подписку следующего содержания: «Я нижеподписавшийся даю настоящую подписку Заведующему Всероссийской сельско-хозяйственной, поземельной и городской переписью в Томской губернии в том, что я, приняв участие в названной переписи в качестве (должность), сим обязуюсь исполнить все распоряжения руководителей переписи на основаниях, изложенных в плане организации переписи в Томской губернии, технической инструкции, а также во всех последующих циркулярах и распоряжениях по делам переписи» $[5$, л. 398]. Данный документ закреплял каждого члена переписной кампании и тем самым фиксировал ответственность в выполнении функционала.

Финансовая сторона вопроса была определена нормативно и предусматривала вознаграждение за труд в следующем размере: окружной инструктор получал 250 руб.; районный - 150 руб.; регистратор - 100 руб. [5, л. 412]. Немало важным был и тот факт, что регистраторам, которых вызывали в определенный пункт для обучения, в случаи принятия их на службу, также засчитывалось со времени выезда их из места жительства в место, где производилось обучение и, кроме того, выплачивали действительную стоимость проезда, по указанным выше нормам лицам.

Таким образом, разработанные технологические механизмы в организации и проведении переписных мероприятий, к числу которых можно отнести сельскохозяйственную поземельную и всероссийскую городскую перепись 1917 года, позволили на качественно новой основе осуществить формирование статистических данных при этом минимизируя неточности и погрешности. Учитывая опыт региональных статистиков и практику их работ, данные инструкции существенно упрощали процесс формирования статистических сведений, пошагово определяя и контролируя всю работу. Во многом синтез накопленного опыта статистических обследований и теории статистического учета позволил организаторам данного мероприятия методически всецело обеспечить всю переписную кампанию. 


\section{ЛИТЕРАТУРА}

1. Скопа В.А. История статистических учреждений Западной Сибири и Степного края в XIX - начале XX века. Барнаул: АлтГПУ, 2015. 412 c.

2. Сема организации земской статистики Сибири: Доклад Общесибирскому областному съезду. Томск, 1917. 24 с.

3. Государственный архив Томской области (ГАТО) Ф 239. Оп. 13. Д. 30.

4. ГАТО Ф. 234. Оп. 1. Д. 308.

5. ГАТО Ф 239. ОП. 13. Д. 32.

6. Терещенко Л.С. Программа разработки материалов Всероссийской сельскохозяйственной и поземельной переписи 1917 г. / Л.С. Терещенко // Труды Московского государственного историко-архивного института. М., 1966. Т. 24. С. $235-249$.

7. Гапоненко Л.С. Материалы сельскохозяйственных переписей 1916-1917 гг. как источник для определения численности населения России накануне Октябрьской революции // История СССР. 1961. № 6. С. 97-115.

8. Вихляев П.А. Конспект лекций по сельскохозяйственной статистике. Ч. 1. Сельскохозяйственные переписи. М.: ИздАТ, 1927. 55 с.

( Скопа Виталий Александрович (sverhtitan@rambler.ru).

Журнал «Современная наука: актуальные проблемы теории и практики»

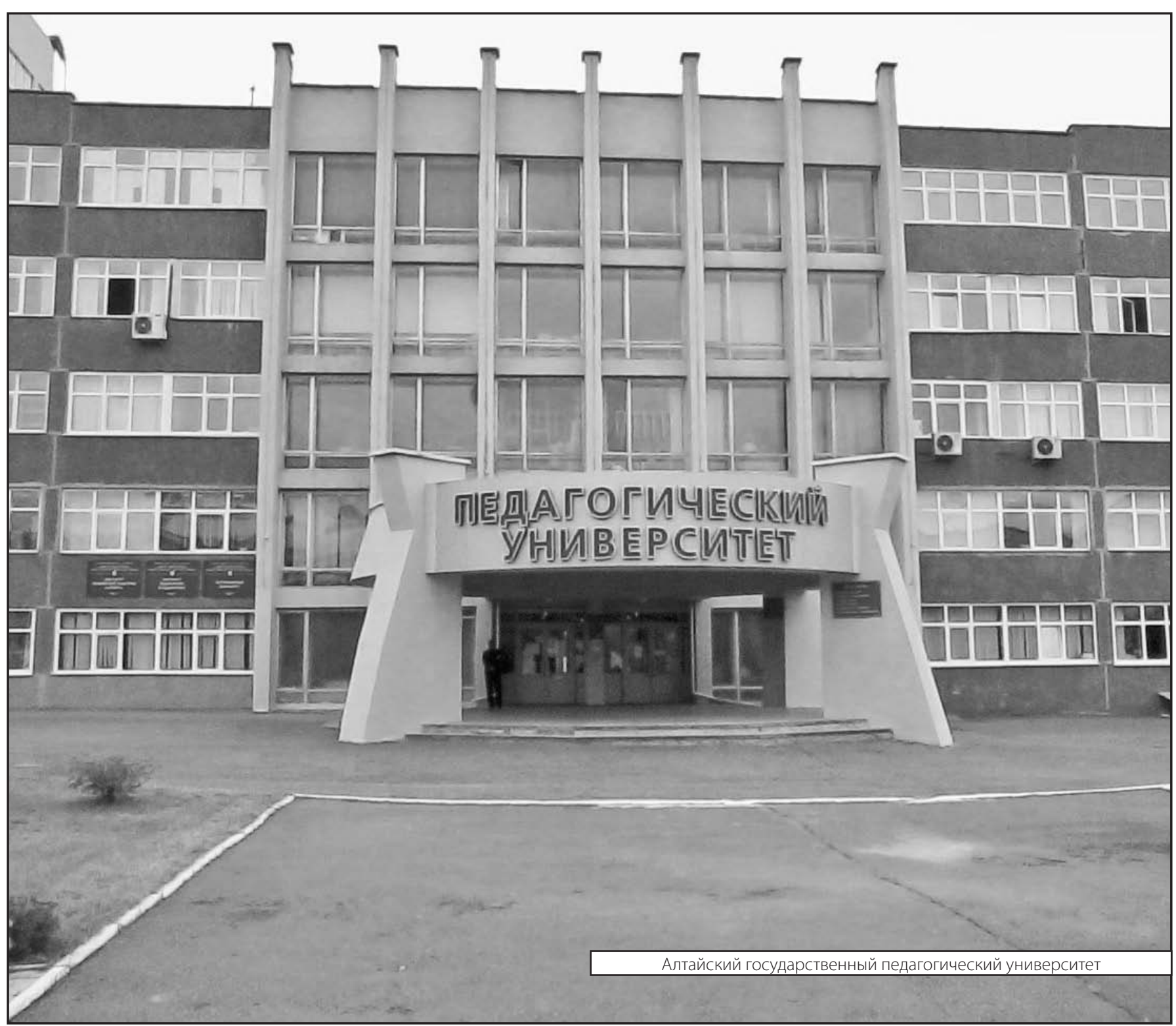

